Cleveland Piggott, MD, MPH; Corey Lyon, DO University of Colorado Family Medicine Residency, Aurora

DEPUTY EDITOR Katherine Hale, PharmD, BCPS, MFA Department of Nursing, Heritage University, Toppenish, WA

doi: $10.12788 /$ jfp.0202

\title{
Antibiotics and COPD: Time to order a C-reactive protein test?
}

\author{
This RCT provided valuable insights as to whether \\ CRP-guided prescribing could safely reduce antibiotic \\ use during acute COPD exacerbations.
}

\section{PRACTICE CHANGER}

Consider C-reactive protein-guided prescribing of antibiotics in acute chronic obstructive pulmonary disease exacerbations in the outpatient setting, as it results in fewer antibiotic prescriptions without adverse effects. ${ }^{1}$

\section{STRENGTH OF RECOMMENDATION}

B: Based on a single randomized controlled trial. ${ }^{1}$

Butler CC, Gillespie D, White P, et al. C-Reactive protein testing to guide antibiotic prescribing for COPD exacerbations. $N$ Engl J Med. 2019;381:111-120.

\section{ILLUSTRATIVE CASE}

A 55-year-old man with a history of chronic obstructive pulmonary disease (COPD) presents to you with increased sputum volume and increased dyspnea, but no fever. You diagnose a COPD exacerbation. Would point-of-care C-reactive protein (CRP) testing be a useful tool to guide antibiotic prescribing?

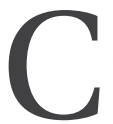

OPD is a common respiratory condition and one of the leading causes of death in the world. ${ }^{2}$ COPD requires chronic therapy and frequent treatment for acute exacerbations. ${ }^{3}$ A systematic review found that exacerbations occur an average of 1.3 times per year for patients with known COPD. ${ }^{4}$ Antibiotics are often prescribed for COPD exacerbations, but which patients benefit most from antibiotic treatment is unclear and identification often is based on clinical features alone. Additionally, overprescribing of antibiotics can lead to unnecessary adverse effects, drive antibiotic resistance, and be a waste of resources. ${ }^{5}$

The European Respiratory Society/ American Thoracic Society (ERS/ATS) provides a conditional recommendation to consider antibiotics in ambulatory patients with COPD exacerbation based on moderatequality evidence. ${ }^{6}$ The 2020 Global Initiative for Chronic Obstructive Lung Disease (GOLD) guidelines recommend antibiotics for moderately or severely ill patients with a COPD exacerbation who have increased cough and sputum purulence. ${ }^{7}$ While the ERS/ATS recommendations do not mention CRP, the GOLD guidelines discuss biomarkers as emerging tools in determining antibiotic utility.

Biomarkers such as procalcitonin and CRP are being examined as potential tools to distinguish which patients would benefit from antibiotic treatment in COPD exacerbations. In a 2013 study, CRP levels $>19.6 \mathrm{mg} / \mathrm{L}$ in the serum and $>15.2 \mathrm{mg} / \mathrm{L}$ in the sputum indicated a bacterial infection, but more research was needed to determine if CRP could help guide antibiotic prescribing. ${ }^{8}$ In a 2019 randomized trial of 101 patients with COPD exacerbations, researchers compared the GOLD strategy for antibiotic prescribing with a CRP-guided antibiotic strategy 
(CRP $\geq 50 \mathrm{mg} / \mathrm{L}$ ) and found no difference in adverse events between study groups. ${ }^{9}$

This trial focused on point-of-care CRPguided prescribing of antibiotics for patients with COPD exacerbations in the outpatient setting.

\section{STUDY SUMIMARY}

\section{Point-of-care CRP testing is noninferior to usual care}

This open-label, multicenter, randomized controlled trial at 86 general medical practices in the United Kingdom examined whether the use of point-of-care CRP testing could reduce antibiotic use during acute exacerbations of COPD. Patients $(\mathrm{N}=653$; 650 needed to provide $81 \%$ to $90 \%$ power) were ages 40 years and older, had a diagnosis of COPD, and presented for an acute exacerbation of COPD based on the presence of at least 1 Anthonisen criteria (increased dyspnea, increase in sputum volume, and increase in purulent sputum).

Patients were randomized in a 1:1 fashion to receive care guided by point-of-care CRP testing (CRP-guided) or usual care for their COPD exacerbation. Patients in the CRP-guided group received a point-of-care CRP test as part of their assessment at presentation, or at any other appointments for COPD over the following 4 weeks.

The research team provided clinicians with CRP interpretation guidance based on the following CRP values: $<20 \mathrm{mg} / \mathrm{L}$, antibiotics are typically not needed; 20 to $40 \mathrm{mg} / \mathrm{L}$, antibiotics might be beneficial if purulent sputum is present; and $>40 \mathrm{mg} / \mathrm{L}$, antibiotics are usually beneficial. Primary outcomes were patient-reported antibiotic use within 4 weeks and COPD-related health status.

Of the patients who received a point-ofcare CRP test, the median value was $6 \mathrm{mg} / \mathrm{L}$; $76 \%$ had a value $<20 \mathrm{mg} / \mathrm{L}, 12 \%$ had values between 20 and $40 \mathrm{mg} / \mathrm{L}$, and $12 \%$ had values $>40 \mathrm{mg} / \mathrm{L}$. In the intention-to-treat analysis, fewer patients in the CRP-guided group reported antibiotic use vs those in the usual-care group (57\% vs $77 \%$; adjusted odds ratio $[\mathrm{aOR}]=0.31 ; 95 \% \mathrm{CI}, 0.20-0.47$ ) within 4 weeks. The CRP-guided group also received fewer antibiotics at the initial visit com- pared to the usual-care group ( $48 \%$ vs $70 \%$; $\mathrm{aOR}=0.31 ; 95 \% \mathrm{CI}, 0.21-0.45$ ).

COPD-related health status was assessed with the Clinical COPD Questionnaire (score range, $0-6$; a difference of 0.4 represents minimal clinical importance). At 2 weeks, the adjusted mean difference in the total health status score with the use of CRP was noninferior to usual care and was in favor of the CRP-guided group (mean difference $=-0.19$ points; two-sided $90 \%$ CI, -0.33 to -0.05$)$. There was no evidence of clinically important betweengroup differences in pneumonia (3\% vs $4 \%$; $\mathrm{aOR}=0.73 ; 95 \% \mathrm{CI}, 0.29-1.82)$ at 6 -month follow-up. Rates of hospitalization at 6 months were similar between groups (9.3\% vs $8.6 \%$; no $P$ value provided).

Limitations of this trial included patient report of antibiotic use and the lack of a sham test.

\section{WHAT'S NEW}

\section{RCT provides evidence \\ to support use of CRP testing}

Point-of-care CRP testing can reduce antibiotic prescribing in patients presenting with a COPD exacerbation without affecting symptom improvement or adverse events.

\section{CAVEATS}

\section{CRP testing may not be cost effective}

CRP testing-especially point-of-care testing -remains expensive in many parts of the United States. A 2015 cost-effectiveness analysis of point-of-care CRP tests for respiratory tract infection in England concluded the cost of the test per patient was not cost effective..$^{10}$ It is unknown if point-of-care CRP testing would be cost effective in guiding antibiotic prescribing for primary care providers with a focus on COPD exacerbations.

\section{CHALLENGES TO IMPLEMENTATION}

\section{Virtual visits and}

\section{variable access may limit use}

CRP-guided antibiotic prescribing may be challenging in some clinical scenarios or clinics with the rise of virtual visits and differ-
Fewer patients in the CRPguided group reported antibiotic use vs those in the usual-care group within 4 weeks. 
ential access in primary care clinics to pointof-care CRP tests.

\section{ACKNOWLEDGEMENT}

The PURLs Surveillance System was supported in part by Grant Number UL1RR024999 from the National Center For Research Resources, a Clinical Translational Science Award to the University of Chicago. The content is solely the responsibility of the authors and does not necessarily represent the official views of the National Center For Research Resources or the National Institutes of Health.

Copyright (c) 2021. The Family Physicians Inquiries Network. All rights reserved.

\section{References}

1. Butler CC, Gillespie D, White P, et al. C-reactive protein testing to guide antibiotic prescribing for COPD exacerbations. $N$ Engl JMed. 2019;381:111-120.

2. Lopez AD, Mathers CD, Ezzati M, et al. Global Burden of Disease and Risk Factors. The World Bank; 2006.

3. Buist AS, McBurnie MA, Vollmer WM, et al. International varia- tion in the prevalence of COPD (the BOLD Study): a populationbased prevalence study. Lancet. 2007;370:741-750.

4. Singh J, Palda V, Stanbrook M, et al. Corticosteroid therapy for patients with acute exacerbations of chronic obstructive pulmonary disease: a systematic review. Arch Intern Med. 2002;162: 2527-2536.

5. Schroeck JL, Ruh CA, Sellick JA, et al. Factors associated with antibiotic misuse in outpatient treatment for upper respiratory tract infections. Antimicrob Agents Chemother. 2015;59:3848-3852.

6. Wedzicha JA, Miravitlles M, Hurst JR, et al. Management of COPD exacerbations: a European Respiratory Society/American Thoracic Society guideline. Eur Respir J. 2017;49:1600791.

7. Global Initiative for Chronic Obstructive Lung Disease. Global Strategy for the Diagnosis, and Management and Prevention of Chronic Obstructive Pulmonary Disease (2020 report). Accessed May 12, 2021. https://goldcopd.org/gold-reports/

8. Peng C, Tian C, Zhang Y, et al. C-reactive protein levels predict bacterial exacerbation in patients with chronic obstructive pulmonary disease. Am J Med Sci. 2013;345:190-194.

9. Prins H, Duijkers R, van der Valk $P$, et al. CRP-guided antibiotic treatment in acute exacerbations of COPD in hospital admissions. Eur Respir J. 2019;53:1802014.

10. Hunter R. Cost-effectiveness of point-of-care C-reactive protein tests for respiratory tract infection in primary care in England. Adv Ther. 2015;32:69-85.

\section{The first mobile job board for Physicians, NPs, and PAs}

\section{Mobile Job Searches - access MedJobNetwork.com on the go from your smartphone or tablet}

\section{Advanced Search Capabilities - search for jobs} by specialty, job title, geographic location, employer, and more

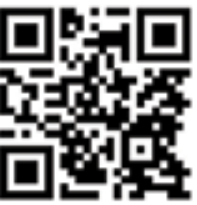

Scan this QR code

to access the mobile version of MedJobNetwork.com 